\title{
O SISTEMA DE PRECEDENTES NO DIREITO PÁTRIO: UMA ANÁLISE À LUZ DO GARANTISMO PENAL ${ }^{1}$
}

\section{THE SYSTEM OF PRECEDENTS IN THE BRAZILIAN LEGAL SYSTEM: AN}

\section{ANALYSIS IN THE LIGHT OF THE CRIMINAL GUARANTEE}

Mariane de Matos Aquino Mestranda em Direito pela Pontifícia Universidade Católica do Paraná, campus Curitiba (2020 -2022). pós-graduanda em direito penal e processo penal econômico pela Pontifícia Universidade Católica do Paraná, campus Londrina (20192021). graduada em direito pela Pontifícia Universidade Católica do Paraná, campus Londrina (dez/2018). membro do grupo de pesquisa em Direito Penal Econômico da Pontifícia Universidade Católica do Paraná, campus Londrina. associada ao Instituto Brasileiro de Ciências Criminais - IBCCRIM. $\begin{array}{lll}\text { Advogada. } & \text { Londrina } & \text { /PR. }\end{array}$ aquinomariane2@gmail.com.

Janaina Braga Norte Pereira Doutoranda em Direito na Pontifícia Universidade Católica do Paraná - PUC/PR (2019). Mestre em direito negocial pela Universidade Estadual de Londrina (2006). Especialista em Direito aplicado (2003). Bacharel em Direito pela Universidade Estadual de Londrina (2002). Professora de Direito Penal e Prática Criminal na Pontifícia Universidade Católica - PUC/PR, campus Londrina e nos cursos de pós graduação lato sensu na Pontifícia Universidade Católica PUC/PR (Direito Penal Econômico e Compliance) e de pós graduação lato sensu em Direito Previdenciário (crimes

\footnotetext{
${ }^{1}$ Artigo recebido em 08/02/2021 e aprovado e 23/04/2021.
} 
previdenciários). Professora convidada da pós-graduação da FEMPAR - Fundação Escola do Ministério Público do Paraná em Londrina (disciplina de legislação penal especial). Membro do núcleo docente estruturante do curso de graduação em Direito da Pontifícia Universidade Católica do Paraná. Coordenadora da pós-graduação lato sensu em Direito Penal e Processual Penal Econômico na Pontifícia Universidade Católica - PUC/PR, campus Londrina. Coordenadora do Laboratório de Ciências Criminais do IBCCRIM (Instituto de Ciências Criminais) em Londrina-PR. Advogada. Londrina PR. E-mail: jbraga@netomartinspalla.com.br.

RESUMO: O trabalho trata dos precedentes judiciais e da sua aplicação no âmbito criminal à luz do garantismo penal. Parte-se da contextualização dos precedentes, da análise da possibilidade de aplicação das normas processuais civis ao processo penal e dos principais desdobramentos do garantismo penal. Assim, objetiva-se verificar se o sistema de precedentes não será utilizado apenas para resolver um problema quantitativo do Judiciário, em detrimento do direito do réu de ter as especificidades do seu caso consideradas pelo julgador. Para tanto, o trabalho foi desenvolvido a partir do método de abordagem hipotético dedutivo, a fim de verificar se a hipótese proposta se confirma.

PALAVRAS-CHAVE: Precedentes. Processo Civil. Processo Penal. Garantismo Penal. Julgamento.

ABSTRACT: This paper addresses the issue of judicial precedents and its application in the criminal procedure in the light of penal guarantee. It begins from the contextualization of precedents, the analysis of the possibility of applying civil procedural rules to criminal proceedings and examine the main developments of the criminal guarantee. Thus, the objective is to verify whether the precedent system will not be used only to solve a quantitative problem in the Judiciary, to the detriment of the defendant's right to have the specifics of his case considered by the judge. For this purpose, the hypothetical deductive 
approach method will be used to find out if the hypothesis can be confirmed before the variables found.

KEYWORDS: Precedents. Civil Procedure. Criminal Proceedings. Criminal guarantee. Judgment.

\section{INTRODUÇÃO}

A Constituição da República Federativa do Brasil de 1988, na perspectiva do constitucionalismo contemporâneo, exige a atuação do Estado no sentido de assegurar direitos e garantias individuais e sociais a todos, não obstante imponha limites ao poder e à atuação estatal. É neste contexto que o presente trabalho se propõe a analisar a possibilidade de aplicação do sistema de precedentes no âmbito criminal, de modo a verificar se é compatível com os direitos e garantias fundamentais imprescindíveis para que o devido processo legal seja observado, e para que a Constituição não seja apenas, nas palavras de Ferdinand Lassalle 2 , "uma folha de papel".

Assim, em um primeiro momento, contextualizar-se-ão o sistema de precedentes e as principais disposições do atual Código de Processo Civil acerca do tema, para, posteriormente, verificar a possibilidade de aplicação das normas processuais civis ao processo penal, de modo a identificar se as previsões do CPC/2015 no tocante aos precedentes também se aplica no âmbito processual penal. Adiante tratar-se-á dos principais desdobramentos do garantismo penal, para que seja possível apurar, com base nos axiomas garantistas, se a aplicação de um sistema de precedentes criminais encontra guarida nesse modelo normativo de direito.

Destarte, a partir da contextualização do sistema de precedentes e dos seus reflexos no processo penal, estabelecer-se-á uma análise de sua aplicação na seara criminal à luz do garantismo penal. Isto porque a operacionalização do referido sistema requer um exame criterioso a respeito das consequências de sua utilização, vez que os direitos e garantias constitucionais precisam ser estritamente observados também nas decisões que se pautam

\footnotetext{
${ }^{2}$ LASSALE, Ferdinand. O que é uma Constituição? São Paulo, 1993, p. 30.
} 
em precedentes judiciais, sob pena de submeter o réu à uma decisão que não compreenda as particularidades do caso concreto.

Por fim, pontua-se que o método de abordagem será o hipotético-dedutivo, a fim de verificar se a hipótese de que é necessário pensar a aplicação de precedentes no processo penal à luz do caso concreto, pode ser confirmada a partir de determinadas variáveis. Acrescente-se, ainda, que a técnica de pesquisa é de documentação direta por meio de análise legislativa, e indireta com base em exame doutrinário.

\section{O SISTEMA DE PRECEDENTES JUDICIAIS}

Inicialmente, é preciso pontuar que a aplicação de precedentes para pautar pedidos e decisões judiciais no âmbito criminal tem sido uma prática cada vez mais frequente, daí então a relevância de examinar as principais noções acerca do sistema de precedentes para que seja possível avaliar se a sua operacionalização no processo penal está em consonância com as lições do garantismo penal.

Em se tratando, precipuamente, de Direito Penal e Processual Penal, a interferência do Estado na esfera de liberdade do indivíduo deve assegurar os direitos e garantias fundamentais, pois os resultados de uma ação penal podem causar marcas que jamais serão apagadas da história do sujeito. Como pontuado por Francisco Muñoz Conde, a gravidade dos meios que o Estado emprega na repressão do delito, a drástica intervenção nos direitos mais elementares, o caráter de ultima ratio que esta intervenção tem, impõe a busca de um princípio que controle o poder punitivo estatal excluindo toda arbitrariedade e excesso do uso do poder punitivo ${ }^{3}$.

Consequentemente, a aplicação de um sistema de precedentes para fins de decisões no contexto criminal não pode estar na contramão do garantismo penal, com a inobservância de direitos elementares que devem ser assegurados ao réu para que o julgamento ocorra dentro dos parâmetros estabelecidos pelo devido processo legal. Sendo assim, para que seja possível avaliar a compatibilidade do uso de precedentes com o sistema normativo de direito abordado neste trabalho, é preciso apresentar breves noções acerca do sistema de

${ }^{3}$ CONDE, Francisco Muñoz. Introducción al Derecho Penal. Buenos Aires: Editorial BdeF Ltda., 2003, p. 135. 
precedentes, de suas técnicas de flexibilização, bem como as disposições do Código de Processo Civil de 2015.

Nesse contexto, a abordagem do referido sistema requer, inicialmente, que se estabeleça a diferença entre os termos jurisprudência e precedente, pois embora sejam usualmente aplicados como sinônimos, não o são. De acordo com a Professora Mariângela Gama de Magalhães Gomes, o termo precedente tem origem no direito inglês, é regra no sistema common law, e corresponde a uma ou várias decisões de um tribunal que podem vincular o próprio tribunal e os juízes que lhes são subordinados, enquanto o termo jurisprudência é originário do direito francês, e compreende o conjunto de precedentes sobre uma determinada matéria ${ }^{4}$.

Assim, segundo Eduardo de Albuquerque Parente, considerando que a jurisprudência é o conjunto de decisões reiteradas, predominantes, provindas de tribunais sobre determinada matéria, a diferença em relação ao precedente consiste no fato de que este pode ou não integrar um conjunto harmônico e reiterado, e não é necessariamente gerado por um colegiado $^{5}$. Isto posto, é necessário destacar, também, que nem toda decisão é um precedente, pois, segundo Teresa Arruda Alvim Wambier, no Brasil, assim como nos países de civil law em geral, as decisões são decisões e não precedentes necessariamente ${ }^{6}$.

Desse modo, verifica-se que nem toda decisão terá força de precedente relevante, pois, para tanto, a situação sub judice deverá ter importância para além das partes envolvidas, na verdade, deve ter relevância nacional. Ademais, a decisão precisa ser bem fundamentada, e a solução deve ser esperada, aí então poderá ser considerada um precedente, é o que acontece, por exemplo, com as decisões proferidas nos julgamentos de recursos repetitivos.

Acrescenta-se que o precedente é uma decisão proferida no passado e que servirá como guia para as ações a serem decididas no futuro, para tanto precisa conter uma tese jurídica com as razões da decisão, parte que efetivamente deve ser observada para que o precedente possa ser aplicado em outros casos. Outrossim, é válido destacar que os precedentes podem ter vinculação vertical ou horizontal, a primeira corresponde àquele

${ }^{4}$ GOMES, Mariângela Gama de Magalhães. Direito penal e interpretação jurisprudencial: do princípio da legalidade às súmulas vinculantes. São Paulo: Atlas, 2008, p.73.

${ }^{5}$ PARENTE, Eduardo de Albuquerque. Jurisprudência: da divergência à uniformidade. São Paulo: Atlas, 2006, p. 5.

${ }^{6}$ WAMBIER, Teresa Arruda Alvim. Brazilian Precedentes. Portal Migalhas, 2014. Disponível em: <https://www.migalhas.com.br/dePeso/16,MI203202,31047-Brazilian+precedentes.> Acesso em: 10 ago. 2018. 
produzido por uma corte superior e que deverá ser seguido pelas instâncias inferiores, enquanto a vinculação horizontal diz respeito a necessidade de se observar o precedente na própria corte para que não haja contradições entre as decisões.

Há também a classificação quanto a eficácia do precedente, que pode ser persuasivo, normativo ou intermediário. De acordo com o artigo 927 do Código de Processo Civil, as decisões proferidas pelos juízos de primeiro grau, acórdãos não proferidos em incidente de resolução de demandas repetitivas ou incidente de resolução de competência, terão apenas eficácia persuasiva, que segundo Luís Roberto Barroso e Patrícia Perrone, é aquela cujos efeitos atingem apenas as partes, porém são importantes para o desenvolvimento da atividade interpretativa e argumentativa, podendo influenciar decisões judiciais ${ }^{7}$.

Por outro lado, as súmulas vinculantes e as decisões proferidas em controle concentrado de constitucionalidade, terão eficácia normativa em sentido forte, isto é, caso algum desses precedentes seja desrespeitado, poderá a decisão ser cassada mediante reclamação, conforme preceitua o artigo 988, inciso III, do Código de Processo Civil. Pontua-se, ainda, que os acórdãos proferidos em casos de repercussão geral e em recurso extraordinário e especial repetitivos, assim como as orientações em caso de incidentes de resolução de demandas repetitivas e de incidente de assunção de competência, não podem ser considerados precedentes com eficácia normativa em sentido forte, vez que não há previsão constitucional autorizando a obrigatoriedade de sua aplicação.

Por fim, as súmulas simples editadas pelo Supremo Tribunal Federal e pelo Superior Tribunal de Justiça, as orientações do plenário e dos órgãos especiais das Cortes, terão eficácia intermediária. De acordo com Luís Roberto Barroso e Patrícia Melo ${ }^{8}$, para esta eficácia o próprio ordenamento atribui efeitos para além dos casos em que foram produzidas, em favor ou desfavor de quem não era parte nestes, ou, ainda, porque o próprio direito determina a observância dos entendimentos ali proferidos ${ }^{9}$. Dessa forma, os efeitos não serão restritos às partes, pois o precedente poderá ser utilizado para pautar outras decisões, porém a não aplicação não poderá ensejar o ajuizamento de reclamação, pois há obrigatoriedade de

\footnotetext{
${ }^{7}$ BARROSO, Luís Roberto; MELLO, Patrícia Perrone Campos. Trabalhando com uma nova lógica: a ascensão dos precedentes no direito brasileiro. Revista Consultor Jurídico, 2016, p. 1. Disponível em: <https://www.conjur.com.br/dl/artigo-trabalhando-logica-ascensao.pdf.> Acesso em: 25 fev. 2017.

${ }^{8}$ BARROSO; MELLO, op. cit, p. 13 e 14.

${ }^{9}$ BARROSO; MELLO, op. cit., p. 13 e 14.
} 
observação, ou seja, de analisar se há ou não adequação do precedente ao caso concreto, e não de aplicação automática do precedente.

Ainda em relação ao Código de Processo Civil, é imperioso destacar que nos termos do artigo $489, \S 1^{\circ}$, incisos V e VI, as decisões não podem se limitar a invocar um precedente sem demonstrar que o caso sub judice se ajusta aos fundamentos determinantes, ou deixar de aplicar um precedente invocado pela parte, sem demonstrar que há distinção em relação ao caso, ou que já houve superação daquele entendimento, daí então a necessidade de utilização das técnicas de flexibilização para a aplicação de todos os precedentes, sejam eles de eficácia persuasiva, normativa ou intermediária.

À vista disso, é preciso considerar dois pontos importantes do sistema de precedentes, a ratio decidendi e o obiter dictum. Para tanto, parte-se, mais uma vez, da explicação da Professora Mariângela Gama de Magalhães, segundo a qual a ratio decidendi, como o próprio nome sugere, diz respeito as razões da decisão ${ }^{10}$, isto é, os motivos que atribuem sentido ao que foi decidido, e tem total importância porque o precedente não é necessário apenas para as partes do processo em que está sendo produzido, já que a ratio decidendi será utilizada em casos futuros, por isso, precisa haver clareza e fundamentação adequada, pois àquelas razões serão aplicadas na prestação da tutela jurisdicional a outros sujeitos.

Ainda sobre a ratio decidendi, é preciso observar alguns elementos importantes para que possa ser identificada. De acordo com Luís Roberto Barroso e Patrícia Perrone, é basilar a análise dos fatos relevantes, da questão jurídica posta em juízo, dos fundamentos da decisão e da solução determinada pela corte, para que assim seja possível concluir pelo entendimento firmado pelo tribunal naquele caso, que será o parâmetro para demais decisões ${ }^{11}$.

Por outro lado, o obiter dictum diz respeito às afirmações que fazem parte da fundamentação, embora não sejam decisivas para a solução do caso, são considerações marginais. Assim, embora o obiter dictum tenha sido utilizado em algum momento na construção da decisão, não teve caráter determinante ao ponto de definir os rumos que

\footnotetext{
${ }^{10}$ GOMES, op. cit., p. 76.

${ }^{11}$ BARROSO; MELLO, op. cit., p. 22.
} 
resultaram naquele decisum, e poderá, inclusive, ser utilizado futuramente na elaboração de novas teses, e aí então se tornar ratio decidendi.

Outro aspecto relevante a ser abordado, é a técnica de distinção de casos, o distinguishing. Consoante as explicações da Professora Mariângela Gama de Magalhães Gomes, no common law, a técnica de distinção possibilita que o juiz diferencie o caso concreto a ser julgado daquele coberto pelo precedente, de maneira que, sob esse fundamento, torna-se possível que a solução dada seja outra ${ }^{12}$. Destarte, a aplicação do distinguishing permite a identificação dos pontos de distinção entre as decisões, o que é extremamente importante, pois as situações fáticas, que são a base de qualquer decisão, são sempre únicas.

Nesta linha, Luís Roberto Barroso e Patrícia Perrone indicam os elementos necessários para avaliar se há semelhança entre dois casos, quais sejam, os fatos relevantes de cada caso, os valores e normas que incidem sobre cada conjunto de fatos, a questão de direito suscitada em cada um, e os fundamentos que justificaram a decisão precedente, assim como a sua adequação para orientar a decisão no segundo caso ${ }^{13}$. Tal análise é primordial para evitar a aplicação de um precedente que não guarde relação com o caso concreto, pois é possível que as peculiaridades do precedente possam não se adequar no momento de sua aplicação ao caso sob julgamento.

Outra técnica valorosa do sistema de precedentes é o overruling, que permite a superação de um precedente. Note-se que esta técnica é diferente do distinguishing, pois, segundo Bustamante, a distinção não implicará no abandono do precedente, apenas no seu afastamento naquele caso, já o overruling revoga ou supera um precedente devido a necessidade de mudança, de atender as novas necessidades, a partir de uma nova construção jurídica sobre determinadas questões ${ }^{14}$. Nesse sentido, o tribunal pode entender ser imperioso revogar determinado precedente, por diversos motivos, como por exemplo, quando não mais atende às necessidades do momento e não for possível readaptá-lo, de maneira que a norma dele decorrente não pode mais ser aplicada daquela maneira.

\footnotetext{
12 GOMES, op. cit., p. 134.

${ }^{13}$ BARROSO; MELLO, op. cit., p. 26.

${ }^{14}$ BUSTAMANTE, Thomas da Rosa de. Teoria do Precedente Judicial: a justificação e aplicação de regras jurisprudenciais. São Paulo: Noeses, 2012, p. 470.
} 
Note-se, portanto, que o sistema de precedentes judiciais é composto por um conjunto de elementos que precisam ser estritamente compreendidos e aplicados, para que seja possível identificar o que é um precedente e suas diferenças em relação à uma decisão judicial comum; os efeitos e os tipos de eficácia; assim como as técnicas de aplicação. A concepção de tais questões é indispensável para evitar a instauração de um sistema de ementas e dispositivos, no qual haja apenas a replicação dos precedentes, ignorando-se a ratio decidendi, as distinções entre o precedente e o caso sob julgamento, bem como podendo causar um engessamento dos posicionamentos judiciais caso o overruling não seja devidamente observado.

\section{O SISTEMA DE PRECEDENTES À LUZ DO CÓDIGO DE PROCESSO CIVIL DE 2015}

Tecidas as referidas considerações acerca do sistema de precedentes judiciais, bem como já apontadas algumas disposições do Código de Processo Civil brasileiro a respeito da temática, faz-se necessário identificar determinadas questões relevantes acerca do sistema jurídico brasileiro e daquele originário dos precedentes, para, após, analisar os principais desdobramentos das previsões legais sobre precedentes no Processo Civil pátrio.

Como sabido, o Brasil adota o sistema jurídico civil law, de origem romano germânica, que tem a lei como a principal fonte de Direito, com comando normativo geral e abstrato que abarca as situações particulares que se adequem às descrições legais. De acordo com Fabiano Pimentel, sobre a origem do civil law, nesse sistema jurídico, o juiz devia respeito à lei, não devendo em nenhuma hipótese afastar-se dela, já que esta era uma forma de controlar as decisões dos juízes, que, após a Revolução Francesa, não gozavam de bom conceito $^{15}$. À vista disso, no civil law, as decisões judiciais, em regra, não produzem efeitos para além dos casos em que são proferidas, e, consequentemente, ocupam papel secundário enquanto fonte do Direito.

Porém, o fato de o sistema civil law ser o adotado pelo ordenamento jurídico brasileiro, não é um empecilho para a adoção de teorias e institutos do common law, cuja

${ }^{15}$ PIMENTEL, Fabiano. A teoria do precedente judicial e sua aplicação ao processo penal. Revista Magister de Direito Penal e Processual Penal, n. 85, v. 15, 2018, p. 20. 
gênese está no direito anglo-saxão, e se difere do civil law, principalmente, devido as fontes de Direito. No common law a principal fonte é formada pelos precedentes que contemplam as normas a ser aplicadas aos demais casos, papel exercido pela lei no civil law. Conforme ensina René David, o jurista inglês, herdeiro dos práticos, desconfia daquilo que ele considera, muito naturalmente, como fórmulas ocas ${ }^{16}$, daí então a importância dos precedentes que já apresentam soluções efetivamente praticáveis.

Dessa maneira, no common law os precedentes têm força normativa e proporcionam segurança jurídica e previsibilidade ao jurisdicionado em relação as decisões, haja vista que a aplicação busca promover soluções semelhantes para evitar decisões contrárias e o uso excessivo de recursos. Por conseguinte, prevalece a teoria do stare decisis - stare decisis et non quieta movere -, isto é, de que "aquilo que foi decidido deve ser mantido", dessa forma, atribui força obrigatória aos precedentes, admitindo-se, é claro, a aplicação do distinguishing e do overruling, bem como a necessidade de se observar a ratio decidendi, vez que o stare decisis não é absoluto.

Note-se que, embora haja peculiaridades e diferenças entre os sistemas, constata-se uma aproximação do ordenamento jurídico brasileiro com a aplicação de técnicas oriundas do common law, como por exemplo, o controle concentrado de constitucionalidade e as súmulas vinculantes, e a adoção de um sistema de precedentes pelo Código de Processo Civil de 2015, que em seu artigo 926, caput, traz o dever de os tribunais manterem sua jurisprudência estável, íntegra e coerente. O que está de acordo com as pontuações de François Rigaux, segundo o qual, por mais profunda que pareça a diferença entre os países de direito escrito e os de direito comum, uma evolução convergente aproximou as duas tradições, com a multiplicação de leis no common law e a construção no civil law de teorias tão inovadoras e audaciosas quanto as da jurisprudência dos países de direito comum ${ }^{17}$.

Dessa maneira, com a aproximação dos sistemas intenta-se, com a adoção de precedentes no Brasil, que os mesmos princípios decisórios sejam aplicados em casos idênticos; que as decisões sejam construídas de acordo com o conjunto normativo e jurisprudencial; que haja mais segurança jurídica e previsibilidade em relação às decisões judiciais; bem como que se resolva o problema numérico-quantitativo do Judiciário

${ }^{16}$ DAVID, René. Os grandes sistemas do direito contemporâneo. Tradução de Hermínio A. Carvalho. São Paulo: Martins Fontes, 2002, p. 406.

${ }^{17}$ RIGAUX, François. A lei dos juízes. São Paulo: Martins Fontes, 2000, p. 153. 
brasileiro, pois a partir da aplicação de precedentes é possível diminuir consideravelmente o número de processos em tramitação e o prazo para a conclusão de cada ação em andamento, entre outros. Por isso, o artigo 926 do Código de Processo Civil de 2015, passou a exigir que os tribunais devem uniformizar sua jurisprudência de modo a mantê-la íntegra, coerente e estável.

À vista disso, o legislador passou a adotar a aplicação de precedentes por meio do artigo 927, do CPC/2015, o que tem trazido benefícios para a concretização dos objetivos previstos no artigo 926, CPC/2015, contudo, deve ser analisado com cautela para que o direito dos jurisdicionados de terem as decisões de seus casos construídas artesanalmente não seja deixado de lado, em prol da aplicação de um sistema de precedentes sem maiores reflexões.

O artigo 927 do CPC prevê que juízes e tribunais observarão as decisões proferidas pelo Supremo Tribunal Federal em sede de controle concentrado de constitucionalidade; as súmulas vinculantes; os acórdãos proferidos em incidente de assunção de competência; de resolução de demandas repetitivas; em julgamento com repercussão geral e de recursos extraordinário e especial repetitivos; assim como as súmulas do Supremo Tribunal Federal e do Superior Tribunal de Justiça; e as orientações firmadas pelo plenário ou pelos órgãos especiais das cortes especiais.

Nesse contexto, faz-se necessário estabelecer uma análise crítica acerca das hipóteses elencadas no artigo 927, CPC/2015, que segundo Hélio Ricardo Diniz Krebs, não se pode afirmar que, em razão desse dispositivo, as decisões e enunciados de súmulas receberam status vinculante, até mesmo porque o caput do mencionado artigo determina a observação pelos juízes e tribunais, o que é constitui uma correção em relação ao texto aprovado pela Câmara dos Deputados, que previa a obrigação de seguir aquelas hipóteses ${ }^{18}$. Assim, há discussões sobre a vinculação das hipóteses previstas no referido artigo, isto é, sobre a obrigatoriedade de aplicação, já que o verbo utilizado no caput foi "observar", de maneira que não haveria uma obrigação de aplicação.

Além disso, o referido artigo apresenta algumas incongruências. Por exemplo, a vinculação dos enunciados das súmulas vinculantes tem previsão no texto constitucional,

\footnotetext{
${ }^{18}$ KREBS, Hélio Ricardo Diniz. Sistema de precedentes e direitos fundamentais. São Paulo: Editora Revista
} dos Tribunais, 2015, p. 181. 
artigo 103-A, assim como as decisões proferidas pelo Supremo Tribunal Federal em controle concentrado de constitucionalidade, nos termos do artigo $102, \S 2^{\circ}, \mathrm{CF} / 88$, por isso, de acordo Nelson Nery Junior e Rosa Maria de Andrade Nery, não há necessidade de o CPC determinar aos juízes e tribunais que cumpram a Constituição e as leis ${ }^{19}$. Ademais, segundo Teresa Arruda Alvim Wambier ${ }^{20}$, há um erro na utilização do termo "acórdão" (art. 927, III, CPC/2015), pois, na verdade, o que deve ser observado é a ratio decidendi.

Além disso, discute-se também que as hipóteses previstas nos incisos III, IV e V do artigo 927, do CPC/2015, diferente das previstas nos incisos I e II, não teriam aplicação obrigatória, isto é, os juízes poderiam ou não utilizá-las, justificando, evidentemente, as razões para tanto, sendo que em qualquer hipótese ter-se-ia observado o precedente, pois observar significa, examinar, analisar, ponderar a respeito da ratio decidendi e dos limites do caso concreto a ser aplicado, logo, observar não significa, necessariamente, a aplicação automática do precedente.

Constata-se também discussões no sentido de que as hipóteses dos incisos III, IV e V do referido artigo, não poderiam ter efeito vinculante, pois não há autorização constitucional para tanto. De acordo com Nelson Nery Junior e Rosa Maria de Andrade Nery $^{21}$, só existe hierarquia jurisdicional do tribunal sobre o juiz no caso de competência recursal, pois a vinculação a preceitos abstratos, gerais, características de lei, só pode ocorrer mediante autorização da Carta Política, e segundo a Constituição nos artigos 102 e 105, o Supremo Tribunal Federal e o Superior Tribunal de Justiça são tribunais que decidem casos concretos, que resolvem lides objetivas e subjetivas ${ }^{22}$. Por isso, considerar os incisos III, IV e V, do artigo 927, CPC/2015, como obrigatórios, seria atribuir ao Superior Tribunal de Justiça e ao Supremo Tribunal Federal um papel de legislador, o que não está previsto no texto constitucional, de modo que as decisões proferidas nas formas dos referidos incisos não podem valer como previsões abstratas e gerais - papel atribuído à lei - quando o constituinte nada disse a respeito.

\footnotetext{
${ }^{19}$ NERY JUNIOR, Nelson; NERY, Rosa Maria de Andrade. Comentários ao Código de Processo Civil. São Paulo: Revista dos Tribunais, 2015, p. 1836.

${ }^{20}$ WAMBIER, Teresa Arruda Alvim. Breves comentários ao novo Código de Processo Civil. São Paulo: Editora Revista dos Tribunais, 2015, p. 2076.

${ }^{21}$ NERY JUNIOR; NERY, op. cit., p. 1836.

${ }^{22}$ NERY JUNIOR; NERY, op. cit., p. 1836.
} 
As breves considerações acerca das previsões do Código de Processo Civil de 2015 demonstram que a aplicação de precedentes não é algo simplório, embora possa contribuir para mais segurança jurídica e previsibilidade, proporcionando coerência, integridade e estabilidade para o contexto jurisdicional brasileiro, verifica-se algumas críticas em relação a forma com que os precedentes foram tratados pelo legislador no CPC/2015. Sendo assim, constata-se que a aplicação de precedente no âmbito processual civil já é marcada por dúvidas e discussões, de modo que é preciso avaliar com rigor a possibilidade de sua aplicação no processo penal, para que não acabe gerando prejuízos para o réu.

\section{A APLICAÇÃO DAS NORMAS PROCESSUAIS CIVIS AO PROCESSO PENAL E AS DISPOSICÕES DA LEI N" 13.964/2019 - "PACOTE ANTICRIME"}

Considerando, portanto, a ampla aplicação de precedentes para pautar pedidos e decisões judiciais, inclusive no âmbito criminal, e especialmente após a promulgação do Código de Processo Civil de 2015, é necessário verificar a possibilidade de aplicação das normas processuais civis ao processo penal, o que depende de algumas considerações, a começar pelo fato de que o Direito é uno e a divisão em ramos é apenas para fins instrumentais e didáticos, consequentemente, as áreas estão inter-relacionadas.

Nesse sentido, o Código de Processo Penal admite em seu artigo $3^{\circ}$, que, eventualmente, haja interpretação extensiva e aplicação analógica das regras previstas no Código de Processo Civil, eis que o Processo Civil e o Processo Penal são divisões do mesmo ramo do Direito, qual seja, o Direito Processual. Francesco Carnelutti, defende que o Direito Processual Penal é uma espécie do "gênero Direito Processual, dentro do qual particularmente se distingue do Direito Processual Civil ${ }^{23 "}$. A título de exemplo, o Código de Processo Penal prevê expressamente a aplicação de determinados dispositivos processuais civis, nos artigos 139, 362 e 790, o que deixa claro que não são áreas estanques, há pontos de intersecção que permitem a instrumentalização das soluções.

Dessa forma, tendo em vista que o Código de Processo Penal e o Código de Processo Civil não estão localizados em ilhas legislativas, é imprescindível estabelecer uma análise

\footnotetext{
${ }^{23}$ CARNELUTTI, Francesco. Sobre una teoria general del proceso. Buenos Aires: EJEA, 1961. p. 55-56.
} 
de determinados pontos previstos no atual Código de Processo Civil, de sorte a se verificar se há compatibilidade com as normas processuais penais, pois, embora não haja isolamento dos ramos, não pode, igualmente, haver discrepância na aplicação das normas processuais civis ao processo penal, principalmente porque este envolve o status libertatis do indivíduo.

Tratando-se, portanto, de processo penal e processo civil, é preciso trazer à baila algumas das reflexões de Francesco Carnelluti, segundo o qual, 90\% do progresso do processo penal consiste na adaptação de conceitos construídos para o processo civil, de modo que a teoria do processo penal dependeria da teoria do processo civil ${ }^{24}$. Carnelluti faz uma parábola do clássico conto de fadas "Cinderela", no qual a Cinderela, aqui chamada de processo penal, se contentava com os vestidos descartados por suas irmãs mais afortunadas, o processo civil, já que o processo penal sempre foi preterido em relação ao processo civil. Nas palavras de Aury Lopes Júnior, ao fazer referência a obra de Carnelluti, “a irmã favorita aqui, corporificada pelo processo civil, tem uma superioridade científica e dogmática inegável ${ }^{25 "}$.

Isto posto, é necessário esclarecer que o diálogo entre os ramos processuais é possível. Contudo, é preciso assegurar a autonomia do processo penal, para que não haja um engessamento nas estruturas próprias do processo civil ${ }^{26}$. Nesse sentido, nem todas as categorias do processo civil podem ser aplicadas ao processo penal, "como se fossem as roupas da irmã mais velha, cujas mangas se dobram, para caber na irmã preterida"27, vez que o processo penal tem suas categorias autônomas, próprias, suas especificidades, trata do "ser", da liberdade, da vida e não do "ter".

Destarte, é possível a aplicação de normas processuais civis ao processo penal, porém deverá ser feita de modo a observar os direitos e garantias fundamentais e assegurar ao réu o devido processo legal, respeitando as especificidades do Direito Processual Penal. Assim, considerando a importância de que o processo penal tenha seus próprios parâmetros para que possa instrumentalizar a aplicação de determinadas disposições do processo civil, é válido destacar a redação e a inserção dos incisos V e VI do $§ 2^{\circ}$ do artigo 315 do Código de Processo

\footnotetext{
${ }^{24}$ CARNELUTTI, Francesco. Cuestiones sobre el Processo Penal. Bologna: Editorial Dott, 1950, p. 17

${ }^{25}$ LOPES JR., Aury. Direito Processual Penal. 11. ed. São Paulo: Saraiva, 2014, p. 57.

${ }^{26}$ Ibidem, p. 58.

${ }^{27}$ Ibidem, p. 58.
} 
Penal, cuja inclusão se deu através da Lei $\mathrm{n}^{\circ}$ 13.964/2019, popularmente conhecida como "Pacote Anticrime".

A previsão dos referidos incisos demonstra a importância da aplicação dos precedentes judicias no processo penal brasileiro, bem como estabelece parâmetros para que a operacionalização não esteja em desacordo com um processo penal democrático e garantista. Nos termos do $\S 2^{\circ}$ do artigo 315 do CPP, não será considerada fundamentada a decisão judicial, seja ela interlocutória, sentença ou acórdão, que, conforme inciso V, limitarse a invocar precedentes ou enunciado de súmula, sem identificar seus fundamentos determinantes nem demonstrar que o caso sob julgamento se ajusta àqueles fundamentos; e, segundo o inciso VI, deixar de seguir enunciado de súmula, jurisprudência ou precedente invocado pela parte, sem demonstrar a existência de distinção no caso em julgamento ou a superação do entendimento.

Sendo assim, de acordo com Rogério Sanches Cunha, se a decisão tem como único ou principal fundamento o precedente, seja ele obrigatório ou apenas persuasivo, e não realiza o necessário distinguishing, será rotulada nula por falta de fundamentação. Do mesmo modo, merece censura a decisão que deixar de seguir enunciado de súmula, jurisprudência ou precedente invocado pela parte, sem demonstrar a existência de distinção no caso em julgamento ou a superação do entendimento. Acrescenta que, tratando-se de precedente vinculante, para que o julgador possa deixar de aplica-lo, é necessário que especifique quais as diferenças entre os casos julgado e em julgamento tornam inadequada essa aplicação (distinguishing), ou, em sendo competente para tal, que indique a superação do entendimento anterior (overruling) ou a limitação de sua abrangência ${ }^{28}$.

Veja-se, portanto, que as mencionadas disposições entabulam a forma com que os precedentes devem ser aplicados no âmbito processual penal, para evitar, por exemplo, que decisões que decretem prisões preventivas estejam pautadas em precedentes de forma genérica, isto é, sem demonstrar a relação da ratio decidendi do precedente com o caso sub judice, o que acontece com certa frequência. A título de exemplo, no habeas corpus $\mathrm{n}^{\circ}$ 620116-SP, o Relator Ministro Rogério Schietti concedeu a ordem para revogar a prisão preventiva do paciente, argumentando que, a Lei $\mathrm{n}^{\circ} 13.964 / 2019$ acrescentou o $\S 2^{\circ}$ ao artigo

${ }^{28}$ CUNHA, Rogério Sanches. Pacote Anticrime - Lei no 13.964/20189: comentários às alterações no CP, CPP e LEP. Salvador: Editora JusPodivm, 2020, p. 297. 
315 do CPP, no qual é destacada a necessidade de motivação concreta das decisões judiciais que analisam a imposição e manutenção da prisão preventiva ${ }^{29}$. À vista disso, verifica-se que não pode, evidentemente, haver uma aplicação automática de precedentes, sem que haja uma relação direta com as razões de ser do caso concreto.

Nesta linha, de acordo com Aury Lopes Jr., a disposição do artigo 315 do CPP, é um grande avanço ao exigir uma fundamentação concreta, individualizada e com uma sanção, e impor vedações que exigem qualidade da decisão; ao não admitir que ela se limite a indicar artigos da lei ou precedentes, enunciados, sem fazer adequação ao caso concreto; que não enfrente os argumentos trazidos pelas partes, ou ainda que deixe de seguir o precedente, etc. ${ }^{30}$. Previsão neste sentido é aquela do artigo $489, \S 1^{\circ}$ do Código de Processo Civil de 2015, que, evidentemente, também pode ser aplicada ao processo penal, como já demonstrado. No entanto, não há como negar a importância de que a exigência de uma decisão fundamentada à luz do caso concreto esteja disciplinada de forma expressa no Código de Processo Penal, instrumentalizando também, dessa forma, a previsão constitucional do artigo 93, inciso IX, de que todas as decisões precisam ser fundamentadas sob pena de nulidade.

Portanto, tendo em vista a importância que tem sido atribuída a construção e aplicação de precedentes no ordenamento jurídico brasileiro, especialmente a partir do Código de Processo Civil de 2015, bem como o fato de não haver disposições específicas a respeito do tema no Código de Processo Penal, verifica-se que a previsão do artigo $315, \S 2^{\circ}$ do CPP, inaugura um espaço relevante para o debate do tema de precedentes judiciais também no processo penal, no sentido de evitar decisões que simplesmente reproduzam a ementa de um precedente de forma automática e mecânica ${ }^{31}$.

${ }^{29}$ BRASIL. SUPERIOR TRIBUNAL DE JUSTIÇA. Habeas corpus n ${ }^{\circ}$ 620116-SP. Relator Ministro Rogério Schietti. Brasília, 14 de outubro de 2020.

${ }^{30}$ LOPES JR., Aury. Direito Processual Penal. São Paulo: Saraiva Educação, 2020, p. 700.

${ }^{31}$ Vide Renato Brasileiro: [...] não raras vezes nos deparamos com decisões judiciais que os invocam, geralmente transcrevendo-se apenas as respectivas ementas no corpo do julgado, sem que o juiz das garantias (ou da instrução de julgamento), porém, tenha o cuidado de fazer uma efetiva contraposição entre o contexto em que o precedente surgiu e o caso sub judice. BRASILEIRO, Renato. MANUAL DE PROCESSO PENAL. 8 ed. rev., ampl. e atual. Salvador: Editora JusPodvim, 2020, p. 1096 


\section{NOÇÕES ESSENCIAIS A RESPEITO DO GARANTISMO PENAL E DA APLICAÇÃO DE PRECEDENTES}

Tecidas as referidas considerações acerca do sistema de precedentes, e tendo em vista a possibilidade de aplicação das normas processuais civis ao processo penal, bem como as previsões incluídas no Código de Processo Penal pela Lei no 13.964/2019 sobre decisões pautadas em precedentes judiciais, é preciso estabelecer determinados pontos acerca do garantismo penal, para que seja possível analisar a aplicação de precedentes à luz das bases garantistas. Pontua-se, inicialmente, que o garantismo é composto por determinados axiomas, que são basilares para o Estado Democrático de Direito, que, segundo Ferrajoli, é aquele em que o poder estatal está ligado à legalidade e vinculado aos direitos e garantias fundamentais. Os axiomas são: ${ }^{32}$ não há punição sem crime; não há crime sem lei; não há lei penal sem necessidade; não há necessidade sem ofensa ao bem jurídico; não há ofensa ao bem jurídico sem ação; não há ação sem culpa; não há culpa sem processo; não há processo sem acusação; não há acusação sem prova; não há prova sem defesa ${ }^{33}$.

Tais máximas servem de limite ao poder punitivo estatal e, consequentemente, tutelam o réu contra a arbitrariedade do Estado, e devem, evidentemente, ser observadas na aplicação de precedentes judiciais no âmbito criminal. A começar pela legalidade que delimita quais condutas, de acordo com a descrição legal, devem receber punição a partir da culpa perpetrada pelo agente, o que exige que o julgador analise o caso sub judice para que possa verificar se realmente há adequação às disposições legais, e se da suposta conduta pode se auferir culpa apta a ensejar uma sanção penal, aplicando-se, portanto, os princípios da legalidade e culpabilidade.

Consequentemente, é preciso que o julgador realize a verificabilidade ou a refutação da tese acusatória, por meio de uma análise concreta do desvio punível, e deverá fazê-lo com base nas provas produzidas nos autos, pois somente assim poderá concluir pela aplicação ou não da pena. Por isso, com base neste axioma, a aplicação de precedentes não pode ser feita de forma automática, isto é, não se admite que apenas se replique um precedente para

\footnotetext{
32 FERRAJOLI, Luigi. Direito e Razão: teoria do garantismo penal. 3. ed., rev. São Paulo: Revista dos Tribunais, 2010, p. 91.

33 Ibidem, p. 91.
} 
fundamentar uma decisão judicial criminal, pois, dessa forma, não terá ocorrido a análise concreta no sentido de verificar se efetivamente houve o desvio punível previsto na lei, terse-á apenas uma aplicação automática de um precedente, que desconsidera as características do caso concreto, o que não pode ocorrer nos termos do inciso $\mathrm{V}$, do $\S 2^{\circ}$ do artigo 315 do CPP.

Outro axioma de relevância para o tema sob estudo é o de que não há culpa sem processo, o qual será assegurado à medida em que o julgamento observar o devido processo legal, que de acordo com Gilmar Ferreira Mendes, está associado à proteção da liberdade e, dessa forma, à noção de legalidade, de maneira que qualquer restrição à liberdade somente pode ser realizada mediante processo e julgamento previamente definidos em lei, tendo sido desenvolvida em diversas ordens constitucionais e incorporada ao conjunto de axiomas fundamentais do constitucionalismo contemporâneo ${ }^{34}$.

O devido processo legal, com previsão no artigo $5^{\circ}$, inciso LIV, da Constituição Federal de 1988, compreende outros direitos fundamentais, pois garante segurança jurídica ao acusado; contempla o princípio do juízo natural; a igualdade processual, que por sua vez garante a paridade de armas entre as partes; o duplo grau de jurisdição, por meio do qual as partes poderão interpor recurso para instância superior com o intuito de corrigir os erros da decisão e buscar a justiça para o caso sub judice; a duração razoável do processo, entre outros.

Também decorre do mencionado axioma o direito da justiça da decisão, já que o artigo 93, IX, da Constituição Federal, exige que as decisões sejam motivadas e fundamentadas, pois somente assim a justiça do caso concreto poderá ser atingida, vez que cabe ao julgador analisar as razões de fato e de direito que envolvem o caso, para assim decidir da melhor forma; entre outros direitos, posto não haver uma definição limitada sobre o devido processo legal. Dessa forma, é preciso que a aplicação de precedentes observe, também, todos os direitos decorrentes do devido processo legal, o que demandará um exame detalhado do precedente, das suas razões, para seja possível identificar a sua similitude com o caso sob julgamento e concretizar, por exemplo, o previsto no artigo 93, IX, CF/88, motivando e fundamento as razões pelas quais aquele precedente se aplica ou não após o

${ }^{34}$ MENDES, Gilmar Ferreira. Comentários ao artigo 5º, inciso LIV, da Constituição Federal de 1988. In: CANOTILHO, J. J. Gomes; SARLET, Wolfgang; STRECK, Lenio Luiz; MENDES, Gilmar Ferreira. Comentários à Constituição do Brasil. São Paulo: Saraiva, 2013, p. 429. 
transcorrer do devido processo legal, tal como as disposições dos incisos V e VI do $\S 2^{\circ}$, do artigo 315 do CPP.

Destaca-se, também, a máxima de que não há prova sem defesa, a qual garante ao réu o contraditório e a ampla defesa - cuja origem está no devido processo legal -, de modo que a validade das provas produzidas pela acusação dependerá da oportunidade conferida ao réu para contradize-las. Portanto, a todo ato produzido deverá ser concedida a outra parte o direito de dar-lhe a sua versão, conforme prevê o artigo $5^{\circ}$, inciso LV, da Constituição Federal, e o artigo $8^{\circ}$ da Convenção Americana de Direitos Humanos, o que evitará decisões arbitrárias. Destarte, a ampla defesa e o contraditório, de acordo com Jacinto Coutinho, é típico de um processo de partes, no qual o julgador mantém-se equidistante delas no exercício da atividade jurisdicional ${ }^{35}$. De acordo com Eugenio Pacelli de Oliveira, os referidos princípios instituem-se como a pedra fundamental de todo processo e, particularmente, do processo penal, é uma cláusula de garantia instituída para a proteção do cidadão diante do aparato persecutório penal ${ }^{36}$.

Sendo assim, para que haja um processo justo, o contraditório e a ampla defesa são elementos essenciais, sem os quais não poderá ser aplicada uma sanção penal, pois não se terá garantido ao acusado os direitos mais básicos, não terá sido assegurada a própria defesa, que é elementar em um Estado Democrático de Direito. Consequentemente, o julgador deverá se pautar no material probatório produzido a partir da operacionalização do contraditório e da ampla defesa, daí então caso haja a aplicação de um precedente judicial na decisão, este precisa ser analisado à luz das provas e particularidades produzidas nos autos, sob pena de se ignorar o resultado da consubstanciação de princípios indispensáveis para o processo penal democrático.

Isto posto, nota-se que os axiomas são reflexos do iluminismo e do liberalismo que deixaram heranças que são a base do garantismo clássico, como por exemplo, a legalidade estrita, a materialidade e a lesividade dos delitos, a responsabilidade pessoal, o contraditório entre as partes, e a presunção de inocência ${ }^{37}$, e estes e outros princípios têm base constitucional e quando devidamente aplicados demonstram a coerência e unidade do

\footnotetext{
${ }^{35}$ COUTINHO, Jacinto Nelson de Miranda. Introdução aos princípios gerais do direito processual penal brasileiro. Revista da Faculdade de Direito da UFPR, n.30, Curitiba, 1998, p. 187.

${ }^{36}$ OLIVEIRA, Eugênio Pacelli de. Curso de processo penal. 9. ed. Rio de Janeiro: Lumen Juris, 2008, p. 28.

${ }^{37}$ FERRAJOLI, op. cit., p. 37.
} 
sistema jurídico, e evitam arbitrariedades, conferindo segurança jurídica ao réu. Por isso, tendo em vista a importância dos axiomas, quando da aplicação de precedentes precisam ser devidamente analisados e considerados, para que os benefícios que possam advir do sistema de precedentes estejam de acordo com as bases constitucionais e legais que garantem a proteção do réu contra arbitrariedade estatal.

Nesta linha, é válido pontuar, ainda, de acordo com Ferrajoli, que as hipóteses acusatórias precisam ser concretamente submetidas a verificações e precisam ser expostas às refutações ${ }^{38}$, por isso, para que o garantismo penal seja assegurado quando da aplicação de precedentes judiciais, é preciso que as particularidades do caso concreto sejam detidamente analisadas pelo julgador, especialmente quando considera a possibilidade de aplicar um precedente no caso sob julgamento, seja para comprovação ou refutação da tese acusatória.

Para tanto é necessário que se observe o material probatório produzido, daí então a imprescindibilidade de que tenham sido observados o contraditório e a ampla defesa ao longo do processo, de modo que a decisão seja construída a partir de uma análise detalhada dos fatos e provas constantes dos autos, pois cada caso é singular e deve ser tratado como tal. Segundo Ferrajoli, o juiz não é uma máquina automática na qual por cima se introduzem os fatos e por baixo se retiram as sentenças, ainda que com a ajuda de um empurrão quando os fatos não se adaptem perfeitamente a ela ${ }^{39}$, por conseguinte, não é admissível uma aplicação de precedentes que estejam destoantes dos axiomas do garantismo penal.

Portanto, os casos devem ser tratados como verdadeiros casos concretos, e é preciso que a decisão para cada um deles seja construída artesanalmente, vez que o juiz não é uma máquina e o réu é um sujeito de direitos e deveres. Sendo assim, deve ser-lhe assegurada uma decisão que abranja as especificidades do seu caso, ou então estar-se-á diante de um cenário repleto de insegurança jurídica. Pois, não existe um “silogismo judicial perfeito", já que, nas palavras de Alexandre Morais da Rosa, nem toda subtração de coisa móvel alheia, mesmo que formalmente verificada, constitui-se, materialmente, em furto, nem justifica a aplicação da pena, dadas as múltiplas variáveis incidentes ${ }^{40}$.

${ }^{38}$ FERRAJOLI, op. cit., p. 41.

${ }^{39}$ FERRAJOLI, op. cit., p. 42.

${ }^{40}$ ROSA, Alexandre Morais da. Você conhece a teoria do caso no processo penal? Revista Consultor Jurídico, 2016. Disponível em: <https://www.conjur.com.br/2016-abr-22/voce-conhece-teoria-processopenal>. Acesso em: 12 ago. 2018. 
Dessa forma, é possível concluir, que para a aplicação de um precedente, o Estadojuiz deve indicar, de forma fundamentada, os motivos pelos quais o precedente deve ser aplicado ao caso sob julgamento, isto é, demonstrar a relação da ratio decidendi do precedente com o caso sub judice, ou quais são as particularidades que diferem o precedente da situação sob julgamento a que se pretende aplica-lo, assim como disposto no artigo 315, $\S 2^{\circ}$, incisos V e VI do Código de Processo Penal. Está claro, portanto, que não pode haver uma aplicação mecânica da lei, do precedente, da jurisprudência, ou então, instaurar-se-á um cenário contrário ao sistema garantista. Ademais, para evitar o mecanicismo das decisões judiciais, é preciso que o julgador dispenda tempo, cognição, e tenha disposição dialética ${ }^{41}$, o que pode não atender, imediatamente, a necessidade de resolver o problema numéricoquantitativo do Poder Judiciário brasileiro. Por fim, sublinhe-se que as decisões proferidas no âmbito criminal, ainda que apliquem precedentes, devem ser construídas à luz do caso concreto, observando todas as particularidades que lhes são próprias, para que os axiomas do garantismo possam ser concretamente observados.

\section{CONCLUSÃO}

O Poder Judiciário brasileiro enfrenta muitos problemas, dentre eles o grande número de processos aguardando julgamento, pautas repletas de casos sensíveis e sem previsão temporal de uma resposta jurisdicional. Porém, a busca por uma solução efetiva para o problema numérico-quantitativo do Judiciário e para a falta de um sistema de decisões íntegras, coerentes e estáveis, deve ser feita respeitando todos os direitos e garantias fundamentais, penosamente conquistados, já que o devido processo legal não pode ser sacrificado em nome da necessidade de "desafogar” o Judiciário.

Nesse contexto, a questão merece ainda mais atenção no que diz respeito ao julgamento de casos criminais, vez que o Direito Penal impõe severas restrições aos direitos fundamentais, pois a sanção penal - a mais drástica de todas - pode restringir a liberdade do sujeito e deixar marcas que não se apagam facilmente - ou nunca se apagam. Ainda assim, tem-se constatado muitas decisões judiciais no âmbito criminal, notadamente em relação a

${ }^{41}$ ROSA, Alexandre de Morais da. Como "cada caso é um caso" em tempos de justiça quantitativa? Revista Consultor Jurídico, 2017. Disponível em: <https://www.conjur.com.br/2017-out-27/limite-penal-cadatempos-justica-quantitativa.> Acesso em: 12 ago. 2018. 
decretação de prisões preventivas, que não se atentam para as particularidades do caso concreto, reduzindo-se, tão somente, a replicar precedentes judiciais de forma automática e sem a observância das técnicas necessárias para tanto, consubstanciando medidas drásticas sem maiores análises e ponderações.

Este problema é reflexo, além de outros fatores, da falta de previsões específicas no Código de Processo Penal que inaugurem um sistema de precedentes criminais, com o estabelecimento de parâmetros e limites precisos sobre o uso de precedentes para fundamentar as decisões nesta seara, já que há apenas uma aplicação por analogia das previsões do Código de Processo Civil, o que prejudica o uso de precedentes no contexto criminal. Por isso, dada a superioridade dogmática e científica do Processo Civil sobre a matéria de precedentes, faz-se necessário discutir e considerar, especificamente, balizas para que a aplicação no processo penal não ocorra em contrariedade ao garantismo, o que consagraria uma aplicação em prejuízo do réu.

Dessa forma, é preciso estabelecer mudanças que resolvam não só o problema numérico-quantitativo, mas também a indispensabilidade de uniformização, estabilização e coerência jurisprudencial. Contudo, conforme mencionado, tais mudanças devem estar pautadas em previsões constitucionais e legais. Nessa conjuntura, o Código de Processo Civil de 1973 foi substituído pelo Código de Processo Civil de 2015, com vistas a proporcionar uma nova perspectiva para o Processo Civil, sendo inegáveis as significativas contribuições trazidas pelo novo sistema processual, porém há pontos que precisam ser mais aprofundados e discutidos, como é o caso da adoção de um sistema de precedentes, principalmente no que diz respeito aos reflexos produzidos no processo penal.

À vista disso, o uso de precedentes criminais deve ser feito com cautela e de forma crítica, no que então verifica-se importante contribuição da Lei no 13.964/2019 - "Pacote Anticrime" ao inserir os incisos V e VI no $§ 2^{\circ}$ do artigo 315 do Código de Processo Penal, pois, embora a matéria processual penal continue sem um sistema de precedentes específico, as balizas dos referidos incisos já contribuem para uma melhor aplicação de precedentes criminais. Dessa maneira, infere-se das referidas previsões a imprescindibilidade de que a observação de um precedente não pode deixar de lado o fato de que é indispensável a construção argumentativa e interpretativa de uma decisão, a partir da observação do 
contraditório e da ampla defesa, para que o julgador possa utilizar os fundamentos fáticos e de direito produzidos pelas partes, e as provas, para confirmar ou refutar a tese acusatória, e dessa forma, proferir uma decisão que possa proporcionar justiça ao caso concreto, aplicando as máximas do garantismo penal.

Afinal, o caso concreto é a razão de existir juízes e tribunais, de modo que a aplicação de um precedente não tira do juiz o dever de interpretar; de construir a decisão com base nas particularidades do caso; de aplicar a melhor solução para a questão apresentada. Senão, o réu será privado de um julgamento justo, de acordo com as particularidades do seu caso, se, por exemplo, o distinguinshing não for feito pelo julgador responsável pela aplicação do precedente; bem como poder-se-á causar um engessamento do Direito com a aplicação automática de precedentes sem que os tribunais responsáveis pela criação de um determinado precedente tenham a possibilidade de realizar o overruling, isto é, revisitar a matéria decidida, rever as razões que levaram àquela decisão e modifica-las ou superá-las, por exemplo, para atender as inauditas questões decorrentes da dinâmica social, política, econômica, e cultural, o que caso não seja feito impedirá a própria evolução do Direito.

Desse modo, conclui-se que diante da importância atribuída aos precedentes judiciais, também no âmbito criminal, pois têm sido utilizados com frequência para pautar pedidos e decisões judiciais, e por vezes de forma automática, replicando-se ementas, e ignorando-se a ratio decidendi e o distinguishing, é preciso considerar balizas específicas para que possam ser aplicados ao processo penal. Isto porque, conforme demonstrado, o sistema de precedentes foi inaugurado e está previsto exclusivamente no Código de Processo Civil de 2015, de modo que não há, com exceção do artigo $315, \S 2^{\circ}$, incisos V e VI, do Código de Processo Penal, previsões especificas e expressas na seara processual penal pátria que disciplinem a forma com que os precedentes devem ser utilizados no processo penal.

Daí então a importância de discutir-se o tema no sentido de buscar nos axiomas do garantismo penal, bem como nos incisos V e VI, do $§ 2^{\circ}$, do artigo 315 do CPP, parâmetros para que as decisões no contexto criminal não se limitem a replicar precedentes de forma automática, sem que haja a análise da ratio decidendi e sem que o distinguishing seja feito caso a caso, considerando as especificidades de cada situação sob julgamento, pois, o réu tem o direito de uma decisão proferida à luz do caso concreto, sob pena de instaurar-se um sistema de ementas e dispositivos contrário aos axiomas do garantismo penal 
Pontua-se, finalmente, que, para além de lidar com o status libertatis do sujeito, a necessidade de discussão sobre a aplicação de precedentes no processo penal, para evitar decisões que se limitem a invoca-los sem identificar seus fundamentos determinantes, nem demonstrar que o caso se ajusta àqueles fundamentos; tal como a importância de estabelecer a distinção ou identificar que o precedente foi superado, como dispõe o $\S 2^{\circ}$ do artigo 315 , do CPP, está justamente no fato de que não há no processo penal brasileiro a instauração de um sistema de precedentes, cuja aplicação tem sido feita com base nas normas processuais civis, daí a cautela para que não haja um engessamento do processo penal nas estruturas próprias do processo civil, e a relevância de se considerar as disposições do artigo $315, \S 2^{\circ}$, do Código de Processo Penal para assegurar uma aplicação garantista

\section{REFERÊNCIAS}

BARROSO, Luís Roberto; MELLO, Patrícia Perrone Campos. Trabalhando com uma nova lógica: a ascensão dos precedentes no direito brasileiro. Revista Consultor Jurídico, 2016. Disponível em: <https://www.conjur.com.br/dl/artigo-trabalhando-logicaascensao.pdf.> Acesso em: 25 fev. 2017.

BRASIL. SUPERIOR TRIBUNAL DE JUSTIÇA. Habeas corpus nº 620116-SP. Relator Ministro Rogério Schietti. Brasília, 14 de outubro de 2020.

BRASILEIRO, Renato. MANUAL DE PROCESSO PENAL. 8 ed. rev., ampl. e atual. Salvador: Editora JusPodvim, 2020.

BUStamante, Thomas da Rosa de. Teoria do Precedente Judicial: a justificação e aplicação de regras jurisprudenciais. São Paulo: Noeses, 2012.

CARNELUTTI, Francesco. Cuestiones sobre el Processo Penal. Bologna: Editorial Dott, 1950.

CARNELUTTI, Francesco. Sobre una teoria general del proceso. Buenos Aires: EJEA, 1961.

CONDE, Francisco Muñoz. Introducción al Derecho Penal. Buenos Aires: Editorial BdeF Ltda., 2003. 
COUTINHO, Jacinto Nelson de Miranda. Introdução aos princípios gerais do direito processual penal brasileiro. Revista da Faculdade de Direito da UFPR, n.30, Curitiba, 1998.

CUNHA, Rogério Sanches. Pacote Anticrime - Lei no 13.964/20189: comentários às alterações no CP, CPP e LEP. Salvador: Editora JusPodivm, 2020.

DAVID, René. Os grandes sistemas do direito contemporâneo. Tradução de Hermínio A. Carvalho. São Paulo: Martins Fontes, 2002.

FERRAJOLI, Luigi. Direito e Razão: teoria do garantismo penal. 3. ed., rev. São Paulo: Revista dos Tribunais, 2010.

GOMES, Mariângela Gama de Magalhães. Direito penal e interpretação jurisprudencial: do princípio da legalidade às súmulas vinculantes. São Paulo: Atlas, 2008.

KREBS, Hélio Ricardo Diniz. Sistema de precedentes e direitos fundamentais. São Paulo: Editora Revista dos Tribunais, 2015.

LASSALE, Ferdinandi. O que é uma Constituição? São Paulo, 1993.

LOPES JR., Aury. Direito Processual Penal. 11 ed. São Paulo: Saraiva, 2014.

LOPES JR., Aury. Direito Processual Penal. São Paulo: Saraiva Educação, 2020.

MENDES, Gilmar Ferreira. Comentários ao artigo $5^{\circ}$, inciso LIV, da Constituição Federal de 1988. In: CANOTILHO, J. J. Gomes; SARLET, Wolfgang; STRECK, Lenio Luiz; MENDES, Gilmar Ferreira. Comentários à Constituição do Brasil. São Paulo: Saraiva, 2013.

NERY JUNIOR, Nelson; NERY, Rosa Maria de Andrade. Comentários ao Código de Processo Civil. São Paulo: Revista dos Tribunais, 2015.

OLIVEIRA, Eugênio Pacelli de. Curso de processo penal. 9. ed. Rio de Janeiro: Lumen Juris, 2008.

PARENTE, Eduardo de Albuquerque. Jurisprudência: da divergência à uniformidade. São Paulo: Atlas, 2006.

PIMENTEL, Fabiano. A teoria do precedente judicial e sua aplicação ao processo penal.

Revista Magister de Direito Penal e Processual Penal, n. 85, v. 15, 2018.

ROSA, Alexandre Morais da. Você conhece a teoria do caso no processo penal? Revista Consultor Jurídico, 2016. Disponível em: <https://www.conjur.com.br/2016-abr22/voce-conhece-teoria-processo-penal>. Acesso em: 12 ago. 2018. 
Rio de Janeiro. Ano 15. Volume 22. Número 3. Setembro a Dezembro de 2021

Periódico Quadrimestral da Pós-Graduação Stricto Sensu em Direito Processual da UERJ

Patrono: José Carlos Barbosa Moreira (in mem.). ISSN 1982-7636. pp. 826-851 www.redp.uerj.br

ROSA, Alexandre de Morais da. Como "cada caso é um caso" em tempos de justiça quantitativa? Revista Consultor Jurídico, 2017. Disponível em: <https://www.conjur.com.br/2017-out-27/limite-penal-cada-tempos-justicaquantitativa.> Acesso em: 12 ago. 2018.

RIGAUX, François. A lei dos juízes. São Paulo: Martins Fontes, 2000.

WAMBIER, Teresa Arruda Alvim. Brazilian Precedentes. Portal Migalhas, 2014. Disponível em: <https://www.migalhas.com.br/dePeso/16,MI203202,31047Brazilian+precedentes.> Acesso em: 10 ago. 2018.

WAMBIER, Teresa Arruda Alvim. Breves comentários ao novo Código de Processo Civil. São Paulo: Editora Revista dos Tribunais, 2015. 